\title{
Analytical framework to evaluate the level of integration of climate adaptation and mitigation in cities
}

\author{
Stelios Grafakos ${ }^{1,2}$ (D) Kate Trigg ${ }^{1} \cdot$ Mia Landauer $^{3,4} \cdot$ Lorenzo Chelleri $^{5}$ • \\ Shobhakar Dhakal ${ }^{6}$
}

Received: 25 June 2018 / Accepted: 14 February 2019 /Published online: 25 March 2019

(C) The Author(s) 2019

\begin{abstract}
Reduction of carbon emissions and climate-resilience in cities are becoming important objectives to be achieved in order to ensure sustainable urban development pathways. Traditionally, cities have treated climate mitigation and adaptation strategies in isolation, without addressing their potential synergies, conflicts or trade-offs. Recent studies have shown that this can lead to inefficiencies in urban planning, conflicting policy objectives and lost opportunities for synergistic actions. However, in the last few years, we have observed that cities are increasingly moving towards addressing both mitigation and adaptation in urban planning. Cities need to pay particular attention and understand the rationale of both policy objectives whilst considering the integration of the two policies in urban planning and decision-making. This study presents an analytical framework to evaluate the level of integration of climate mitigation and adaptation in cities' local climate action plans. We tested this framework in nine selected major cities, representatives from all inhabited continents, which are frontrunners in climate action both in their regions and globally. We applied the framework in order to evaluate the level of mitigation and adaptation integration in cities' CCAPs and further explored the different types of mitigation - adaptation interrelationships that have been considered. A scoring system was also devised in order to allow comparing and ranking of the different CCAPs for their level of integration of adaptation and mitigation. The paper draws good practices to support cities in developing climate change action plans in an integrated way.
\end{abstract}

Electronic supplementary material The online version of this article (https://doi.org/10.1007/s10584-01902394-w) contains supplementary material, which is available to authorized users.

Stelios Grafakos

grafakos.s@gmail.com

Extended author information available on the last page of the article 


\section{Introduction}

Whilst being centres of social innovation and economic development, cities are major contributors to greenhouse gas emissions (GHGs) globally. It is estimated that between 71 and $76 \%$ of $\mathrm{CO}_{2}$ emissions from global final energy use and between 67 and $76 \%$ of global energy use is contributed by urban areas (Seto et al. 2014). Additionally, with large accumulations of inhabitants, technology, infrastructure and economic assets, cities are also more vulnerable to climate change impacts such as extreme temperatures, flooding, droughts and intense storms (The World Bank 2010). At the same time, cities are a key part of the solution too, through emerging networks, peer to peer learning, technological innovation and championing the implementation of solutions for tackling climate change (Pattberg and Widerberg 2015).

Within the variety of actions that can be taken for addressing climate change in cities, it is worth defining and distinguishing emission mitigation and adaptation to climate change impacts. Whilst both policies aim to address different types of climate change issues, the characteristics of the adaptation and mitigation actions on the ground differ greatly (as synthesised in Table 1). However, with carbon concentrations in the atmosphere rising to irreversible levels that may not be stabilised to safe limits with current mitigation targets, both types of measures need to be implemented simultaneously in order to ensure that we address climate change systematically and effectively (Klein et al. 2007) (Table 2).

The integration of climate change adaptation and mitigation planning and actions is critical to ensure that these are mutually reinforcing, to realise synergistic efficiencies, to maximise the impact of limited city resources and to minimise any potential conflicts that could lead either to maladaptation or malmitigation. Whilst there is growing interest in and encouragement of integration, it remains challenging for cities to identify issues and opportunities in integration and to know what the drivers behind decision-making approaches and implementation mechanisms of the two policies are. More understanding of these is needed to ensure that effective integration that would maximise the synergies and minimise the conflicts of adaptation and mitigation takes place.

There are several studies at the national level suggesting that national-level policies must address and recognise mitigation-adaptation interrelationships, and explore the balance (Berry

Table 1 Differences between climate adaptation and mitigation policies (adapted from Dang et al. 2003)

\begin{tabular}{|c|c|c|}
\hline & Mitigation policy & Adaptation policy \\
\hline Sectoral focus & $\begin{array}{l}\text { All sectors that can reduce } \\
\text { GHG emissions }\end{array}$ & $\begin{array}{l}\text { Selected ones related to particular } \\
\text { climate impacts }\end{array}$ \\
\hline $\begin{array}{l}\text { Geographical scale } \\
\text { of effect }\end{array}$ & Global & Local, regional \\
\hline Temporal scale of effect & Long term & Short to medium term \\
\hline Level of governance & International, national & Regional, local \\
\hline Effectiveness & $\begin{array}{l}\text { Certain (with regard to the } \\
\text { reduction of GHG emissions) }\end{array}$ & Less certain \\
\hline $\begin{array}{l}\text { Ancillary benefits } \\
\text { (or co-benefits) }\end{array}$ & $\begin{array}{l}\text { Multiple ancillary benefits that } \\
\text { can be accrued }\end{array}$ & $\begin{array}{l}\text { Often ancillary benefits accrue even } \\
\text { in the absence of climate impacts }\end{array}$ \\
\hline Actor benefits & Through ancillary benefits & $\begin{array}{l}\text { Almost fully through reduction of } \\
\text { climate impact and ancillary benefits }\end{array}$ \\
\hline Polluter pays & Yes & Not necessarily \\
\hline Monitoring & $\begin{array}{l}\text { Relatively easy (measuring the } \\
\text { reduction of GHG emissions) }\end{array}$ & $\begin{array}{l}\text { More complex (measuring the reduction } \\
\text { of climate risk) }\end{array}$ \\
\hline
\end{tabular}


Table 2 Illustrative examples of climate adaptation and mitigation interrelationships

\begin{tabular}{|c|c|c|c|}
\hline $\begin{array}{l}\text { Type of } \\
\text { interrelationship }\end{array}$ & Action/measure & $\begin{array}{l}\text { Primary } \\
\text { objective }\end{array}$ & Interrelationship explained \\
\hline Co-benefit & $\begin{array}{l}\text { District heating and cooling } \\
\text { system }\end{array}$ & Mitigation & $\begin{array}{l}\text { District cooling can be used also in warm } \\
\text { months to adapt to high temperatures }\end{array}$ \\
\hline Synergy & $\begin{array}{l}\text { Construction of green } \\
\text { walls and rooftops }\end{array}$ & $\begin{array}{l}\text { Adaptation } \\
\text { and } \\
\text { mitigation }\end{array}$ & $\begin{array}{l}\text { Green walls and rooftops increase energy } \\
\text { efficiency of buildings and decrease } \\
\text { water run off }\end{array}$ \\
\hline Conflict & $\begin{array}{l}\text { Densification of urban } \\
\text { structure }\end{array}$ & Mitigation & $\begin{array}{l}\text { Dense urban structure reduces green areas } \\
\text { suitable for natural flood protection } \\
\text { measures }\end{array}$ \\
\hline Trade-off & Urban zoning & $\begin{array}{l}\text { Adaptation or } \\
\text { mitigation }\end{array}$ & $\begin{array}{l}\text { Challenges to set priorities in urban } \\
\text { planning due to space limitations in } \\
\text { cities }\end{array}$ \\
\hline
\end{tabular}

et al. 2014; Leonard et al. 2016; Klein et al. 2005; Stoorvogel et al. 2004; Landauer et al. 2015). Past studies on such linkages are focused on AFOLU and REDD+ (de la Torre et al. 2009); conservation (Di Gregorio et al. 2016; Locatelli et al. 2015), agroforestry (Duguma et al. 2014a) and agriculture (Aguilera et al. 2013; Bryan et al. 2010; Kassam et al. 2012; Palm et al. 2010). Few sectoral studies exist on such interlinkages too (Kengoum and Tiani 2013) and enabling conditions (Dang et al. 2003; Duguma et al. 2014b).

When compared to international and national institutions, local governments and cities are increasingly becoming emerging global climate governors (Gordon and Acuto 2015), also through more direct governance structures (Bulkeley and Betsill 2003). Whereas many cities now develop and publish Climate Change Action Plans (hereafter referred to as CCAPs), the majority remain focused on mitigation actions. In 2013, Reckien et al. evaluated 200 large- and medium-sized city CCAPs in Europe and found out that $35 \%$ of the sample have no mitigation plan, whereas $72 \%$ have no adaptation plan. It should be stated here, though, that often climate adaptation actions are included in disaster risk reduction and management plans but are not necessarily called as such.

Furthermore, different studies show that mitigation actions receive the main portion of the global climate finance by international multilateral development aid organisations and development banks. Between 2010 and 2011, 96\% of available funding was allocated to these activities (Buchner et al. 2012; Schwarze et al. 2018). Reasons for this could originate from past focuses of political processes such as the UNFCCC, where mitigation was the key policy to address climate change (Grafakos et al. 2018). More funding is required for adaptation methods to ensure both climate adaptation and mitigation are addressed appropriately. This is especially important to vulnerable developing countries (Duguma et al. 2014b). The gradual policy shift towards adaptation can be also observed in the international climate policy debate, particularly regarding discussions on climate finance, vulnerability and the loss and damage debate (Mechler et al. 2019; Mechler and Schinko 2016). In addition, there is a recent trend where national and local governments are developing climate adaptation action plans or combining adaptation and mitigation (hereafter Ad/Mit) policy objectives in an integrated climate change action plan (Duguma et al. 2014b; Aylett 2015).

An increasing number of cities, within Europe and globally, are slowly shifting from addressing adaptation and mitigation separately towards combining these policies. Based on an extensive survey of 350 local governments' plans globally addressing climate change, 
Aylett (2015) found that $39 \%$ of the plans address both policies. A more recent study by Reckien et al. (2018) shows that out of 885 urban CCAPs reviewed in Europe, 153 CCAPs $(17 \%)$ combine adaptation and mitigation.

Climate change adaptation and mitigation measures are interrelated-in some cases positively (synergies), in others negatively (conflicts) - and sometimes decisions on implementation are based on difficult trade-offs, thus necessitating choices between conflicting policy and planning goals (Klein et al. 2007). Indeed, if addressed as stand-alone policy goals, adaptation (i.e. building coastal flooding protection barriers) and mitigation (i.e. reducing fossil fuel dependency) strategies could lead to trade-offs, development lock-ins or unexpected conflicts (Chelleri et al. 2015), where one action focusing on adaptation could hinder the progress of the mitigation action or vice versa (Klein et al. 2007). For example, tackling water scarcity through a desalination plant could drive the lock-in of the city to increased fossil fuel energy consumption (adaptation at the expense of mitigation), or recent investments in North African transnational long-term projects based on concentrated solar power plants (requiring up to 35001 per megawatt hour generated) could enhance water scarcity in arid territories (mitigation action on expense of adaptation) (Chelleri et al. 2014). A further discussion on the trade-offs involved in climate change adaptation policy can be further found in Henstra (2015). On the contrary, a co-benefit occurs when a plan, policy or measure that aims to enhance an adaptation (mitigation) objective leads simultaneously to the enhancement of mitigation (adaptation) objective. For the purposes of this study, a synergy is understood as an interaction between an adaptation and a mitigation plan, policy, strategy or practical measure that produces an effect greater than the constituent components. A conflict is a plan, policy or measure that counteracts or undermines one or more planning goals between adaptation and mitigation. A trade-off is a situation that necessitates choosing (balancing) between one or more desirable, but sometimes conflicting, plans, policies or measures.

There are many advantages for a combined consideration of adaptation and mitigation, especially at the local level where benefits are more visible, since cities should prepare for current extreme weather events, whilst also reducing long-term climate change impacts (Grafakos et al. 2018). Economically, integrating both measures can be beneficial, if they are improving the cost-effectiveness of planning (Schwarze et al. 2018) and reducing resource competition (Tol 2005), for instance. Combining the measures is difficult due to the numerous stakeholders and sectors involved in planning, decision-making and implementation of actions (McEvoy et al. 2006). However, the dual consideration helps identify potential maladaptation or malmitigation or conflicts between specific plans, which also allows for further reflection of cross-sectoral plans (Barnett and O'Neill 2010). Additionally, this allows the consolidation of holistic understanding compared to separate policies and sectorial decision-making (Grafakos et al. 2018).

Where there are many advantages of simultaneously considering both climate adaptation and mitigation, there are few studies that have explored and identified the different types of interrelationships between the two policies in urban areas. Landauer et al. (2015), based on an extensive literature review, identified interrelationships (synergies and conflicts) of adaptation and mitigation measures at different levels in urban planning, such as policy and organisational levels. The paper also reviewed common synergies and conflicts that occur in specific sectors including energy, building and infrastructure solutions. Demuzere et al. (2014), based on empirical evidence, identified the most common co-benefits and trade-offs between adaptation and mitigation services provided by green urban infrastructure. Duguma et al. (2014b) developed an analytical framework to assess the enabling conditions for synergies at 
the national level and applied it to developing countries to explore the potential that these countries have towards addressing the synergies of adaptation and mitigation policies. A more recent study by Landauer et al. (2018) empirically examined how different scales drive interactions of adaptation and mitigation in cities and found that in particular, interactions taking place at jurisdictional-management scale and institutional-management scale reveal trade-offs and conflicts between adaptation and mitigation. Furthermore, the authors concluded that there is lack of legislation or guidelines on how to consider both policy areas simultaneously that would allow local actors to realise integrated solutions.

\subsection{Aim of the study}

Where there are only few studies addressing adaptation and mitigation interrelationships at the city level, at present, there is a lack of systematic approach or framework to evaluate the level at which adaptation and mitigation are being integrated into cities' CCAPs in order to maximise synergies and avoid conflicts and seek a balance between the two policy objectives. Such a framework is useful to improve both urban planning and governance effectiveness (Landauer et al. 2015), especially due to scale differences in policy implementation (Landauer et al. 2018).

This paper bridges the gap by presenting a framework, including a scoring system, to identify and evaluate the level of integration of adaptation and mitigation (Ad/Mit) in cities' climate action plans. The Ad/Mit framework has been developed by means of a review of the relevant academic literature on climate change action planning and various CCAPs globally. Of these plans, we have selected nine to evaluate in depth, on how the plans integrate adaptation and mitigation, and at which level. Furthermore, we make the hypothesis that cities that have been engaged in climate change planning for some time achieve higher levels of integration of adaptation and mitigation. To investigate this, a short desk study was completed to identify when each city's first CCAP was published.

\section{Analytical framework to evaluate the level of integration of adaptation and mitigation in CCAPs}

There is an emerging body of literature of reviews and evaluations of local climate change action plans mainly looking at their quality, content and policy objectives. More specifically, different scholars evaluate climate change actions in Europe (Reckien et al. 2015, 2018; Heidrich et al. 2013) and North America (Bassett and Shandas 2010; Guyadeen 2018), adaptation plans (Baker et al. 2012, Araos et al. 2016; Aguiar et al. 2018), mitigation strategies (Croci et al. 2017; Heemann and Grafakos 2018) and ecosystem services (Hansen et al. 2015; Geneletti and Zardo 2016); most of the studies analysed the two concepts separately at the sectoral, local and/or national level, in Europe and beyond (Bosello et al. 2010). Our study builds upon and contributes to the current body of literature by evaluating the quality of the local climate change action plans from the perspective of integration of adaptation and mitigation.

There are three main stages in urban climate planning (Moser and Ekstrom 2010; Bizikova et al. 2011; Grafakos et al. 2018): (i) identifying and understanding stage, (ii) envisioning and planning stage and (iii) implementation, management and monitoring stage (see also Fig. 1). 


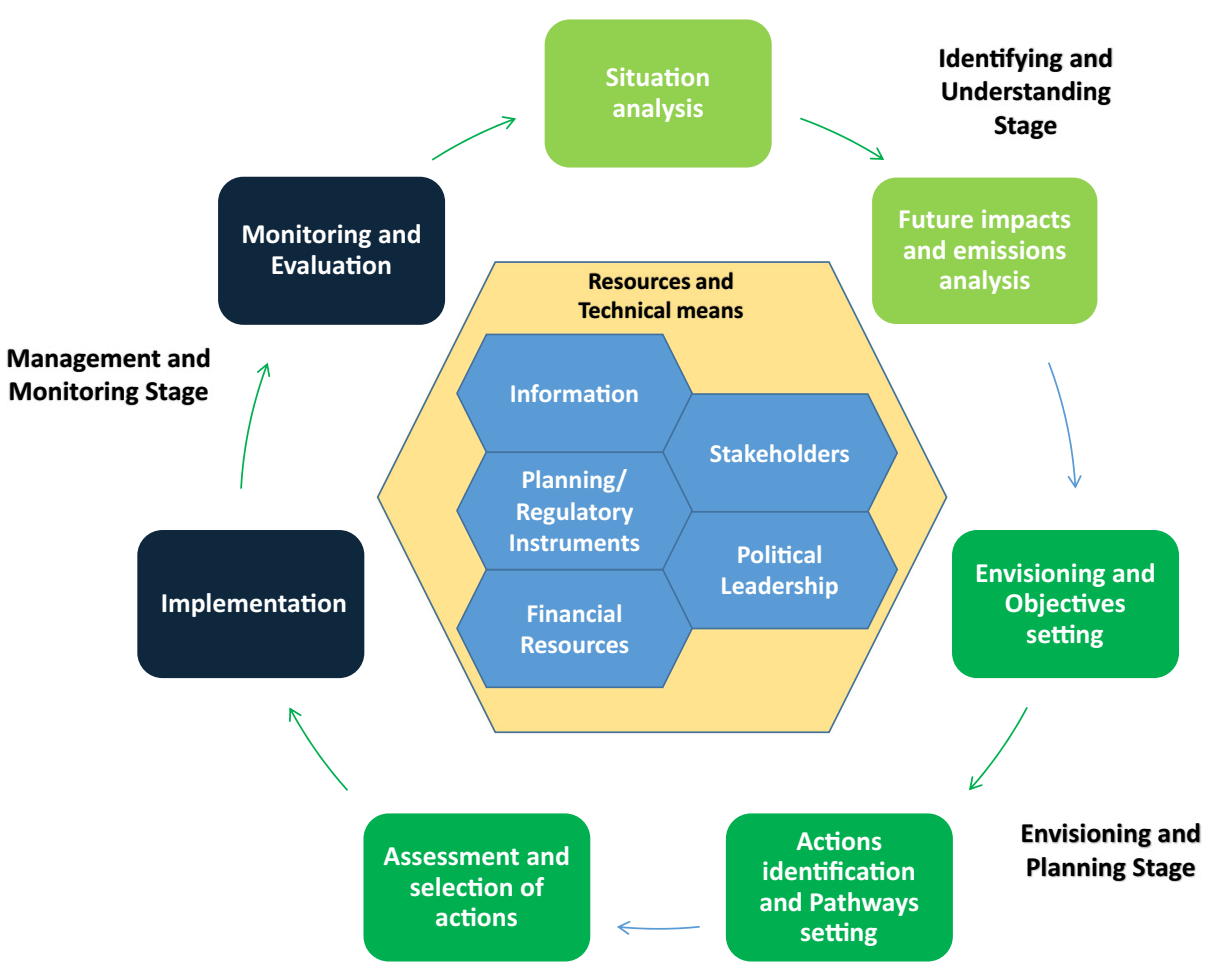

Fig. 1 Stages of integrated urban climate change planning (Grafakos et al. 2018)

\subsection{Identifying and understanding}

To begin climate change planning, a situation analysis should take place to identify current data for the city, which will take different forms depending on the climate change measures. Sufficiently disaggregated city-level and, whenever possible, metropolitan-level GHG emission profiles or inventories are the starting point for climate mitigation planning through characterisation of emissions and adequate sectoral breakdowns at both municipal and community level (Sippel 2011; Millard-Ball 2012). For adaptation planning, vulnerability profiles through maps and indicators at appropriate spatial scales allow the identification of climate risk probabilities, taking into account vulnerability factors such as exposure, sensitivity and adaptive capacity.

Forecasts of future emissions and future climate impacts also require consideration. For example, the current and projected growth of multiple sectors should be reported, in addition to estimates of the probabilities of risk outcomes, damages and their financial costs throughout the city.

Uncertainty of future climate impacts at the city level is one of the main challenges that municipal governments must address. Climate hazards are often differentiated according to their temporal scale: (1) extreme events (immediate and short-term) such as floods, heat waves, landslides and storm surges and (2) long-term (annual/decadal) climate threats such as variations in average temperature or other slow-onset events such as sea level rise. 


\subsection{Envisioning and planning}

Policymakers and urban planners need to set specific goals and targets based on the policy objectives for adaptation and mitigation. This can be particularly challenging with regard to the difference in spatial and temporal scales of adaptation and mitigation planning and implementation (Moser 2012; Landauer et al. 2018). Often, cities set long-term emission reduction targets up to 2030 or even 2050, disaggregated in different urban sectors.

An important step in planning for climate change is the identification of different adaptation and mitigation measures or different portfolios (combinations) of measures, considering possible alternative pathways for meeting cities' climate-resilient and low-carbon development objectives (Klein et al. 2007) and how they interrelate with one another. Mitigation and adaptation actions (or portfolios of actions) are assessed against their costs and benefits or by multiple objectives and criteria, whereas trade-offs between different objectives can be also identified and assessed, a process often called prioritisation (Grafakos et al. 2018). To conduct these, economics-based approaches, including cost-benefit analysis and cost-effectiveness analysis can be applied (Cartwright et al. 2013; Gouldson et al. 2015), as well as integrated approaches such as multi-criteria analysis and integrated modelling (Haque et al. 2011; Walsh et al. 2013; Scrieuciu et al. 2014; Grafakos et al. 2016) and sectoral approaches (Charoenkit and Kumar 2014).

Finally, communication of the decided plan is also important, often taking the form of information or public education campaigns, allowing for engagement and collaboration with the plans (Burch 2010a).

\subsection{Management and monitoring}

Implementation of different climate change actions (particularly the structural ones) can be costly, therefore a clear budget allocation and financial commitment for financing climate actions are imperative for implementation (Schwarze et al. 2018). Since financing adaptation actions could be competing with financing mitigation actions, the establishment of a common budget or funding body could be an efficient way to best allocate existing budgets (Duguma et al. 2014b).

Institutional and jurisdictional divergences between adaptation and mitigation measures can become obstacles to an integrated climate policy approach (Tompkins and Adger 2005; Landauer et al. 2018). Therefore, a common policy or regulatory framework could enhance the integration of adaptation and mitigation. Moreover, a common implementation body could also ensure a more efficient combined implementation of adaptation and mitigation actions (Shaw et al. 2014; Duguma et al. 2014b).

Implementing both adaptation and mitigation actions require the involvement of a range of institutions and departments but also the creation of partnerships with different urban actors and stakeholders such as civic society and the private sector (Burch 2010b; Broto and Bulkeley 2013). Additionally, mainstreaming climate actions into existing plans (e.g. sectoral plans, development plans) can help to ensure proper implementation and accountability (Swart and Raes 2007).

Monitoring and evaluation systems can be used to track and evaluate results before, during and after implementation, enabling improvements and modifications through feedback processes. In this stage, the level of achievement of the climate change adaptation and mitigation objectives is measured through information and data collection for monitoring and evaluation (Brown et al. 2016; Grafakos et al. 2018). 


\section{Methodology}

\subsection{Methods and data}

In this study, nine urban CCAPs were reviewed and their content was analysed thoroughly. All inhabited continents are represented by at least one action plan, as synthesised in Supplementary Table 1. Of these plans, six combined both adaptation and mitigation (Bangkok, Chicago, Mexico, Montevideo, Seoul, Wellington), whilst two primarily focused on adaptation (Durban and Vancouver) and one focused primarily on mitigation (Paris). CCAPs were considered appropriate secondary data for this study as they are (a) comprehensive local-level documents addressing climate change issues; (b) documents that are globally and straightforwardly comparative; (c) official documents prepared by the responsible bodies for addressing climate change within a specific city. Of the CCAPs analysed, seven were in English, and two were in Spanish. Supplementary Table 1 provides background information regarding the selected CCAPs that were analysed. The selection criteria were as follows: (i) major cities, (ii) 'frontrunner' or 'model' cities globally or regionally, with regard to experience on local climate change action planning and (iii) addressing both adaptation and mitigation in their CCAPs, even if the primary focus is either on adaptation (e.g. Vancouver) or mitigation (e.g. Paris).

Based on a desktop study, the CCAPs were reviewed and their content was analysed and evaluated by applying the analytical framework developed for the purpose of this study, as discussed in Section 2. The integrated planning process for climate change in the cities was operationalised in three different stages and associated variables in order to assess the level of integration of Ad/Mit. Indicators were specified to allow us to gauge whether the selected variables were considered in the three planning stages, assessing the level of integration of climate adaptation and mitigation in the CCAPs. Guidelines and score explanations were developed to ensure all researchers conducted the CCAP reviews with the same analysis.

Each variable from the three planning stages can be found in Supplementary Table 2, with its respective score. For most variables, responses were in binary form - if an indicator was fulfilled, the CCAP was given a score of 1 . If an indicator was not fulfilled, or there was no evidence of the indicator being considered, the CCAP received a 0 . Furthermore, seven variables were based upon a scoring scale of $0-2$ as these indicators did not return yes/no responses. Annex 1 illustrates how the variables 'GHG emissions forecast', 'Vulnerability profile', 'Future climate projections', 'GHG emissions reduction targets', 'Consideration of Ad/Mit interrelationships', 'Mainstreaming of both Ad/Mit actions' and 'Common monitoring procedure/framework' were scored. From those seven variables that are measured according to the $0-2$ score scale, two variables are related to adaptation, two variables are related to mitigation and three variables are related to integration-related aspects. If one city scores 2 in all of these variables, it means that it is more integrated, as it scores highest in the three integrated variables and also in both adaptation and mitigation variables that are wellcombined and balanced.

The final stage on management and monitoring entails most of the integrated variables and therefore, a higher score at this stage will mean higher integration. Furthermore, three of these variables are measured in a $0-2$ score scale.

One researcher conducted the reviews of six CCAPs and guided the review of the remaining three to ensure consistency. All scoring decisions were justified using qualitative 
information from the CCAPs. If any discrepancies became apparent during the review analysis, the wider research team discussed the findings to resolve these issues.

In addition to analysing the CCAPs for the variables, we investigated whether a CCAP has explicitly stated co-benefits, synergies, trade-offs or conflicts between Ad/Mit within the plan and identified the sectors that the interactions have occurred.

Whereas the aim of this paper is to consider urban CCAP properties and not to compare one against the other; good CCAP practices are highlighted with examples from the selected plans. Furthermore, the framework can be used to compare CCAPs regarding the level of integration of adaptation and mitigation in the planning process.

\subsection{Limitations}

The aim of the study was to develop and test an evaluation framework of the level of integration of adaptation and mitigation on urban CCAPs and therefore, the application was tested at a small sample of CCAPs from cities distributed across different continents. A simple and sound scoring methodology has been tested in order to provide a clear policy message about the need of linking Ad/Mit, and of course, more insights could be provided from the application of the evaluation framework to larger samples of CCAPs. As illustrated above, the paper builds on a binary (yes/no) assessment which could not explore, nor capture the range of all possible measures effectiveness within the synergistic approach between $\mathrm{Ad} / \mathrm{Mit}$ or quantify and measure the trade-offs. Rather, its usefulness stands in providing an overall assessment avoiding development lock-ins, enhancing climate resilience mainstreaming and guiding further research and policy actions.

\section{Results and discussion}

\subsection{Identifying and understanding}

The results regarding the variables of 'GHG emission profiles', 'GHG emissions forecast' that focuses on mitigation and 'vulnerability profile' and 'future climate projections' that focus on adaptation are displayed in Fig. 2. ${ }^{1}$ Furthermore, the variables that reflect a combined approach such as 'Both emissions profile and vulnerability profile' and 'Both emissions forecast and climate projections' are also depicted in the same figure. A graph presenting the results for all variables within this planning stage can be seen in Annex 3.

As can be seen from Fig. 2, Eight of the nine selected CCAPs contain long-term climate projections in a simple or more sophisticated way. Surprisingly, the CCAP that excluded this projection was the combined Bangkok plan, whereas Paris' mitigation driven plan discusses the rise in average temperature and increased risks or agricultural drought. In Durban, the CCAP discusses the expected temperature and precipitation increases up to 2100 , and Vancouver's CCAP provides an appendix detailing climate model projections to a 19611990 baseline for 2050 and 2080.

\footnotetext{
${ }^{1}$ All framework graphs are colour-coded. Blue-coloured bars represent stand-alone mitigation variables, redcoloured bars represent stand-alone adaptation variables, green-coloured bars represent variables that reflect integration of mitigation and adaptation and grey-coloured bars represent variables applicable to adaptation and mitigation.
} 


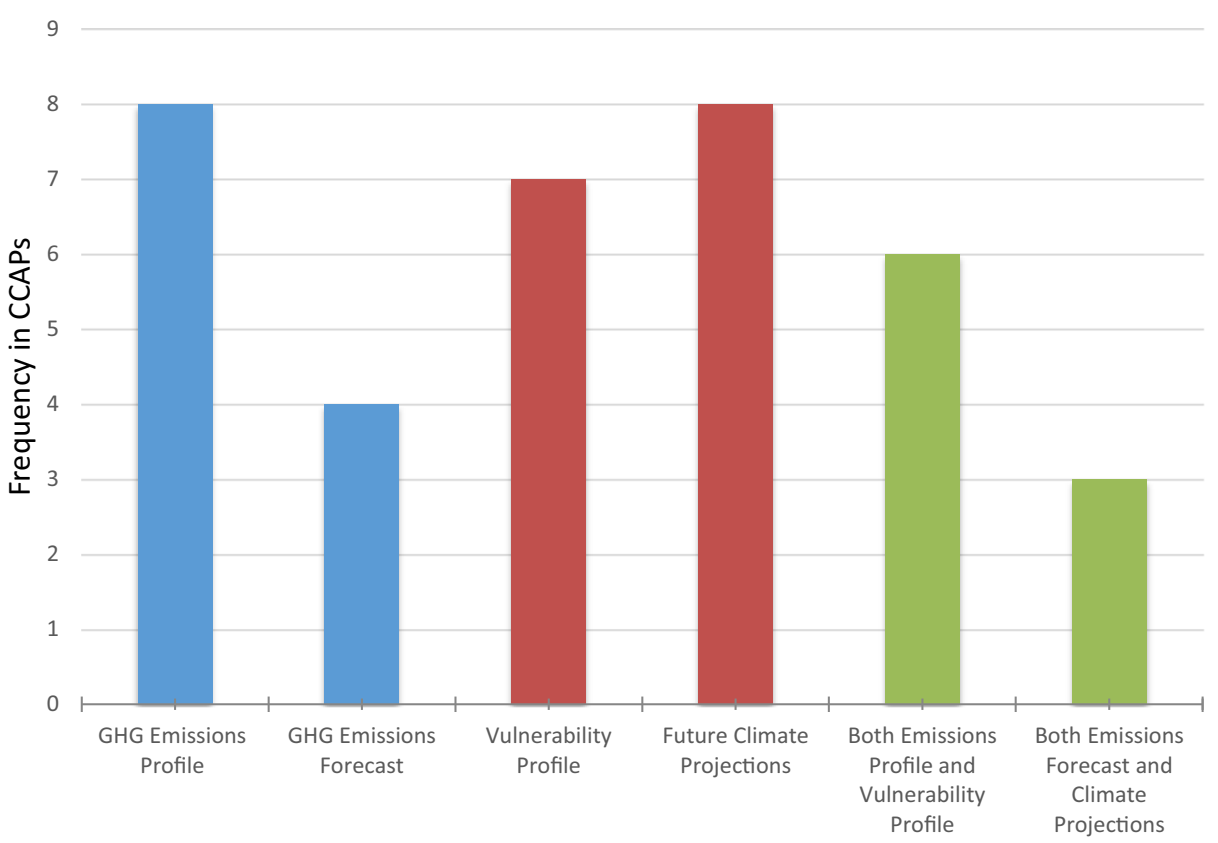

Fig. 2 Frequency of selected variables found in the CCAPs within identifying and understanding stage

Additionally, all CCAPs apart from Vancouver include a GHG emission profile until the year of publishing the report. However, out of these eight action plans, only Chicago, Montevideo, Mexico City and Bangkok advanced further to discuss the forecast of emissions in a 'business-as-usual' scenario at any time span, with Chicago stating that GHG emissions would increase by $35 \%$ in 2050 and Mexico City predicting a linear projection to the midterm date of 2025.

When considering the vulnerability profiles, Durban raised the threats to the city in a chapter on 'Projected changes in Durban's climate and associated impacts', whilst Vancouver provided a coherent vulnerability and risk assessment within its second appendix. The CCAP of Paris provided detailed information on the city's vulnerability although the focus was mainly on mitigation.

It was also interesting to consider which cities identified and measured both mitigation- and adaptation-related factors for their action plans. As can be seen in Fig. 2, six cities have conducted and included in their CCAP both GHG emissions and vulnerability assessments. It was less common (three out of nine) though for a CCAP to include a GHG emissions forecasting and future climate projections, with only Mexico City, Montevideo and Chicago including these.

\subsection{Envisioning and planning}

From the eight variables considered within the envisioning and planning stage, the five that are related to target setting, prioritisation and communication can be seen in Fig. 3. A graph presenting the results for all variables within this planning stage can be seen in Annex 3. An obvious observation from this graph is the low number of CCAPs containing cost estimates to implement the actions stated in the plans. Based on the results, it is evident that even in large 


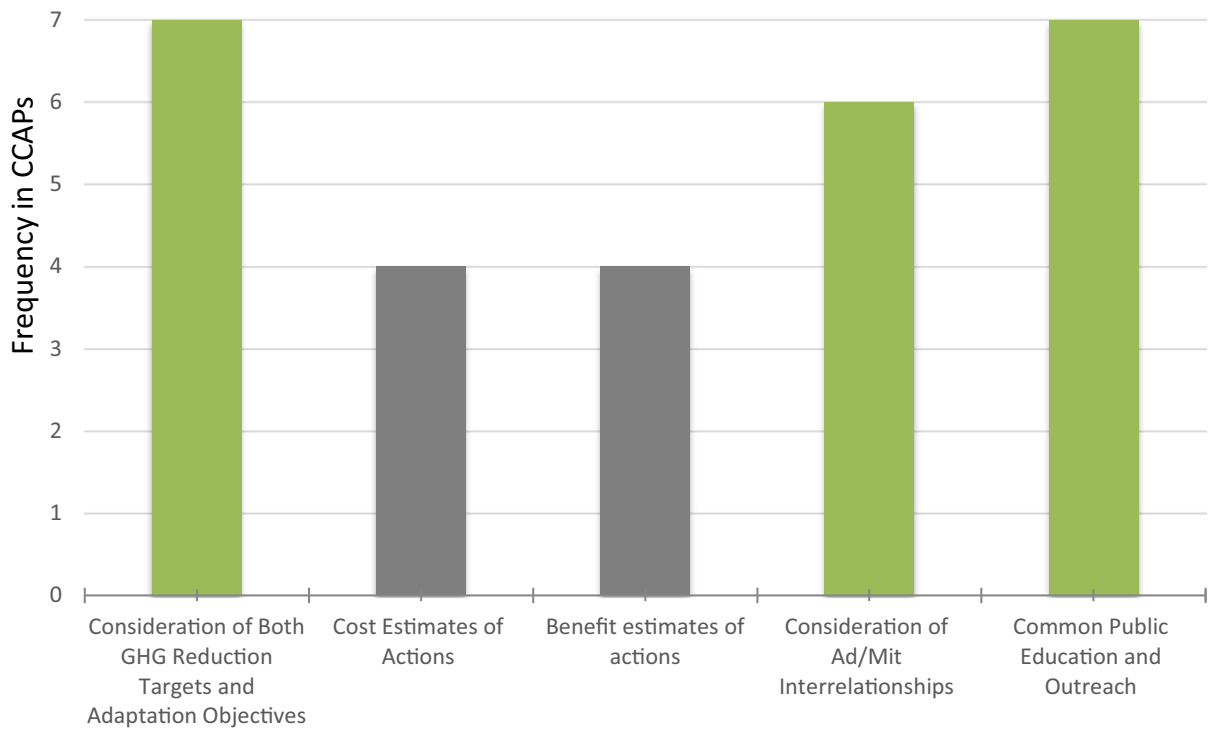

Fig. 3 Frequency of selected variables found in the CCAPs within envisioning and planning stage

cities with a lot of resources, the estimation of costs for climate actions is lacking, whereas in some cases, costs are important criteria within decision-support assessments. For our research questions, the most important variables to consider are 'Consideration of both adaptation and mitigation actions' and 'Adaptation and mitigation interrelationships considered'. All CCAPs do refer to both actions to combat GHG emissions and reduce vulnerability for climate change, and seven of the CCAPs include both GHG emissions reduction targets and adaptation objectives. However, mitigation actions appear far more frequently than adaptation actions. For example, in the Chicago Climate Action Plan, out of 35 actions to address the challenge of climate change, 26 actions are focusing on mitigation (in sectors such as energy-efficient buildings, improved transportation, clean energy sources and reductions of pollution), and only nine actions are focusing on adaptation.

Furthermore, six CCAPs explicitly state interrelationships between adaptation and mitigation, with Paris, Seoul and Mexico City not explicitly stating any interrelationships. Montevideo's CCAP contains an entire chapter on transversal actions fostering adaptation and mitigation integration and the adoption of the plan within the metropolitan region. The interrelationships with their respective sectors are discussed in Section 4.5. Lastly, seven out of nine CCAPs state a common public education, outreach programme.

\subsection{Management and monitoring}

Figure 4 presents all variables used to assess the level of integration in the CCAPs related to financing, implementation and monitoring. From the variables, only two are considered standalone-financing commitment and partnerships. From the graph, it can be seen that some 


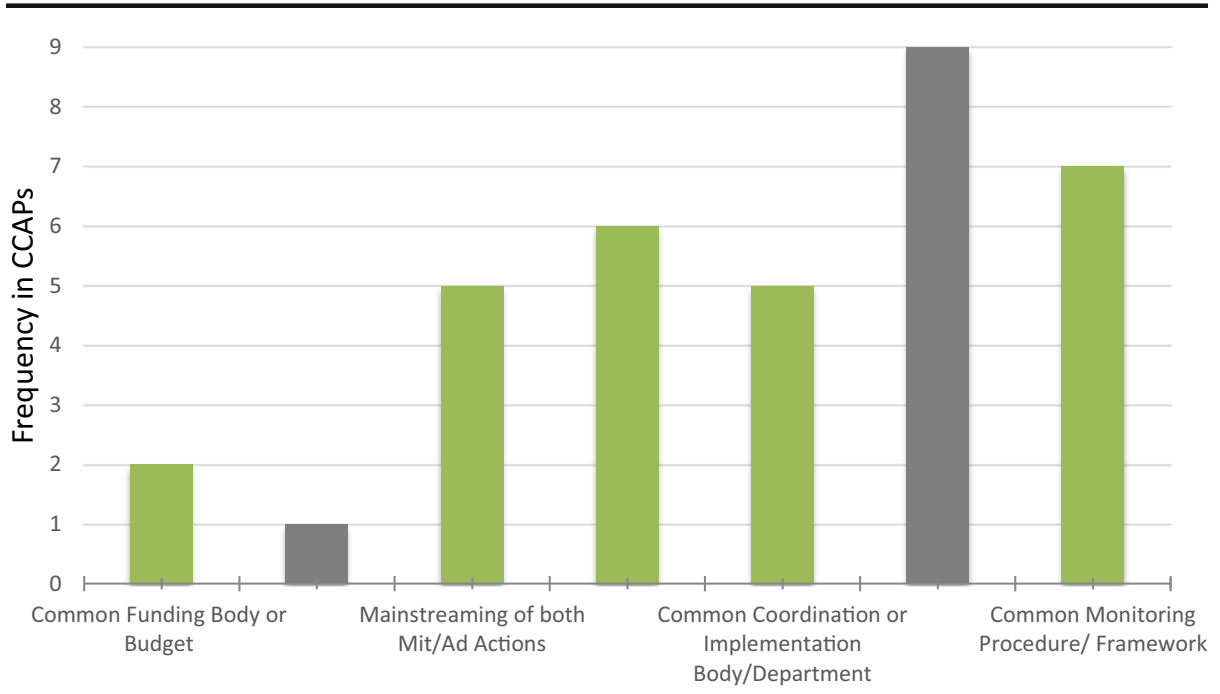

Fig. 4 Frequency of selected variables found in the CCAPs within management and monitoring stage

variables have been more widely considered than others. For example, all CCAPs have a partnership in some fashion, whether this is with a private organisation, international initiatives or other city governments nationally and internationally. Additionally, all cities except Wellington and Montevideo have set up common monitoring frameworks to observe and evaluate their actions. Wellington's plan only states monitoring of the results of mitigation actions.

However, other aspects have not been considered with both mitigation and adaptation in mind. Mainstreaming is discussed in all CCAPs, but potential for both mitigation and adaptation mainstreaming was identified in five. Based on this outcome, it seems that although CCAPs are stand-alone plans, the cities reviewed realise the importance of mainstreaming for effective and efficient implementation. For example, Paris discusses how the Climate Action Plan, particularly the adaptation-related measures, can be linked to other municipal action such as the Biodiversity plan, however, we cannot infer from the CCAP if mitigation actions are also being considered for mainstreaming.

Finance-related topics again are rarely stated at all, with only Seoul confirming a precise financial commitment to each of their actions. Wellington and Vancouver have raised that elements of their plans have been budgeted for, but there is no confirmation of whether this money is being allocated. Within Durban's CCAP, there is currently no funding available and the plan has the aim to find financial backing for the implementation of its key priorities.

Common funding bodies appear to be also rarely established. Wellington has established a common funding body for the implementation of the CCAP, whereas Chicago utilises new funding sources for financing all CCAP activities. Montevideo's plan states that each department should begin working on short-term projects within their own budget where longer projects will depend on external funding from governmental or investors' capital. The fact that finance-related topics are rarely addressed in the CCAPs, could also explain why so many CCAPs remain aspirational. According to Landauer et al. (2018), the lack of financial resources of city administrations can hinder policy integration and trade-offs appear in case of new investments when decisions on allocation of (limited) funds are made. Furthermore, the operating rules of tendering can hinder integrated solutions because the calls for tenders are sometimes too narrow to invest in both adaptation and mitigation. 
One variable that was found frequently (five times) was the common coordination or implementation body. Whereas the CCAPs may detail both mitigation and adaptation actions, different sectors are often responsible for different goals. For example, in Durban, although the strategy will be led by the eThekwini Municipality's Energy Office and the Environmental Planning and Climate Protection Department, a broad range of implementers and stakeholders will carry out the plans, such as other local authorities, local businesses and community-based organisations. Whilst these stakeholders can concentrate fully on their sections of the action plan, it becomes increasingly difficult to monitor and evaluate progress during the implementation and actions from one organisation could unintentionally conflict with other arrangements. As can be seen in Fig. 4, five of the CCAPs state a common (Ad/Mit) coordination/implementation body.

As the results indicate, the majority of the CCAPs do provide common (Ad/Mit) monitoring procedures; however, with many stakeholders being involved in the plan and little quantification on the level of integration in the reports regarding would be successful outcomes of the various aims, it will be difficult to analyse and evaluate success in these action plans.

\subsection{Main adaptation-mitigation interrelationships identified}

Within the action plans, there are certain sectors where synergy (or co-benefit) interrelationships were frequently identified and stated, including:

\section{- Urban Greening}

- Green roofs cooling the city as temperatures rise could retain water during storms, contributing to building climate resilience through a decentralised water management paradigm, whilst increasing energy efficiency of buildings [Climate Change Adaptation Strategy, Vancouver].

- Whilst enhancing forest sinks can increase carbon sequestration, it also helps the city meet objectives on biodiversity protection and will reduce groundwater runoff when rainfall increases [Wellington City's 2013 Climate Change Action Plan].

- Urban agriculture

- Encouraging local, innovative food production using sustainable farming practices allows a city to provide for communities affected by natural disasters. Additionally, transporting this food will convey a lower carbon footprint [Durban Climate Change Strategy].

- Promoting sustainable farming also allows for the soils in the region to sequester more carbon dioxide from the environment [Plan Climático de la Región Metropolitana de Uruguay].

- Water management

- With the increase of extreme heat in summer and flooding risks causing polluted bodies of water, Chicago aims to make sure buildings and inhabitants use water wisely. Retrofitting buildings will increase water efficiency in addition to reducing energy use for pumping, heating and distributing the water [Chicago Climate Action Plan].

Annex 4 lists all interrelationships that were identified in the nine analysed CCAPs. As can be seen and based on our small sample, urban greening actions (including urban forestry, green roofs 
and permeable surfaces) are the most commonly identified actions that generate adaptation and mitigation synergies. Although which climate actions can be implemented in different cities is context specific, it would be worth investigating, by using a larger sample of cities, which actions are identified in most cities generating adaptation and mitigation synergies and conflicts. In addition, we do not see cities coming up with new actions to address both adaptation and mitigation. Instead, we observe cities recognising and more systematically considering the dual or multiple benefits of certain actions, which in certain cases leads to prioritising them as was the case in Vancouver and Durban. Moreover, it is worth investigating why interactions occur in certain sectors. Perhaps climate issues are already institutionally organised and treated as one area of operations (e.g. water management). This could mean that a single department is likely to view climate change mitigation and adaptation holistically rather than independently. As was found by Landauer et al. (2018), in cases where city administrations or departments are responsible either for adaptation or mitigation, it is more unlikely to find holistic solutions ("silo thinking"). Studies based on interviews or surveys could investigate further the issue and provide further evidence.

Furthermore, additional co-benefits related to economic gains, quality of life and public health are also raised within the CCAPs, at times more frequently than the co-benefits between adaptation and mitigation actions.

Another topic to raise is that Durban is the only CCAP that refers to trade-offs or conflicts between adaptation and mitigation actions, stating 'It should be noted that some of the themes in the Strategy are not always mutually supportive, with some responses that may be appropriate for a specific theme negatively impacting the objectives of a different theme'. The CCAP states a trade-off between mitigation and adaptation, relating to localised energy generation and the potential increase of air pollution in the city. In a similar fashion to the absence of related costs, the CCAPs appear to conceal valuable, yet undesirable information to present a wholly progressive action plan.

There are also instances where with knowledge on the sector and evidence from other cases, potential synergies could be identified, which have not been stated within the CCAPs. An example of this is conversions to multiple renewable energy power plants in Chicago and Paris, reducing GHG emissions and dependency on a single energy source. In another example, Paris' CCAP states that the city intends to maintain its high urban density. Whereas this reduces the energy use from transport, this can result in a need for more air conditioning and reductions in green and blue space in the urban environment. Identifying these 'implied' co-benefits and conflicts is beyond the scope of this study. Many of the synergy and conflict examples from the Landauer et al. (2015) study could have also been incorporated into the CCAPs; however, it is important to highlight that identifying co-benefits and conflicts is a demanding task that requires specialised technical capacity, which city officials do not necessarily have.

When considering the CCAP sample, Seoul's CCAP looks quite different from the rest regarding action detail and explanation. In total, the CCAP lists 160 actions to combat climate change in five different sectors, with an almost even split between adaptation and mitigation actions. However, the Seoul CCAP provides no descriptions of how the actions will be implemented, or whether the action is aiming to reduce emissions or increase resilience, making it difficult to detect or imply interrelations on one hand and monitor their implementation on the other.

\subsection{Final scoring of CCAPs}

In addition to assessing the frequency of each variable within the investigated CCAPs, we also calculated the final score of each CCAP according to the devised scoring system. The aim of the 
scoring is not to compare the CCAPs with each other, but to provide insights about the level of integration of Ad/Mit in CCAPs. A higher score means a higher level of integration of adaptation and mitigation in the three levels of climate change action planning which further means that it is more likely the city to realise the advantages of integration. On the other hand, better integration does not mean necessarily higher chances for implementation, although we could hypothesise this. Follow-up research could investigate to which extent higher $\mathrm{Ad} / \mathrm{Mit}$ integration contributes to higher chances for CCAP implementation.

The results can be seen in Fig. 5; an additional column presenting the maximum possible score of 28 is included for comparison.

28

24

23

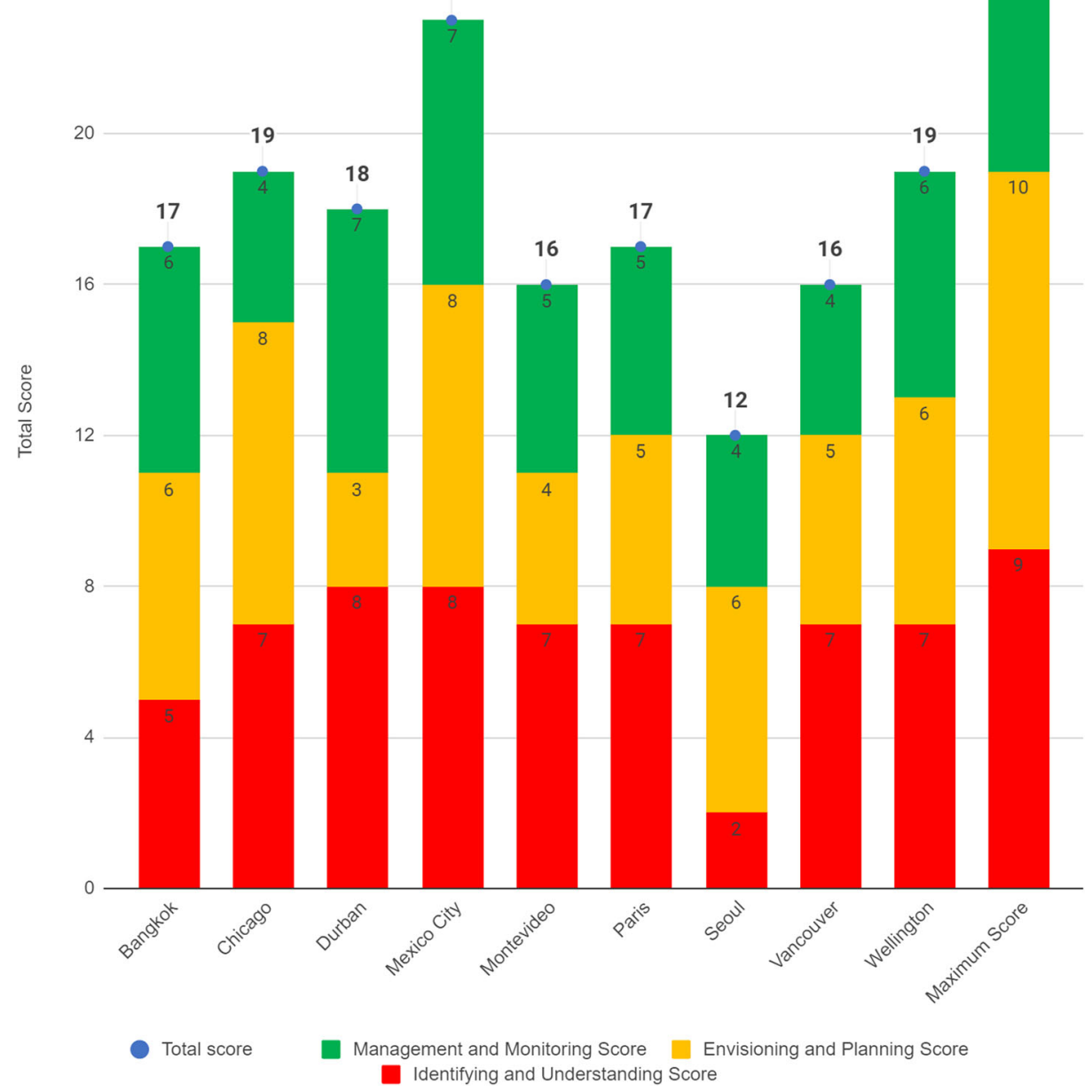

Fig. 5 Final scores of CCAPs regarding the level of integration of Ad/Mit 
Mexico City's CCAP achieved the highest score of 23 out of the maximum possible 28, scoring highly in all three planning stages. Durban performed equally well within two planning stages; however, the city's CCAP did not present adaptation and mitigation integration within its Envision and Planning elements. Nonetheless, Durban, in addition to Vancouver and Paris (whose CCAPs were driven solely on either mitigation or adaptation) scored comparably to the mean average score of 17 . These CCAPs demonstrate that even when the primary focus of a CCAP is either on adaptation or mitigation, a level of integration can still be achieved. Seoul scored low within the framework as the CCAP's format kept adaptation and mitigation actions separated and stand-alone.

Regarding our hypothesis that cities with longer engagement in climate change planning, achieve higher level of integration, the hypothesis stands true for Mexico City and Wellington, whose first CCAP was published 6 years before their current reports, but it is contradicted by Seoul whose first CCAP was released in 2009. A larger CCAPs study would need to be conducted to test this hypothesis. It could also be hypothesised that a city under a directive from an upper tier government to adopt a CCAP may result in higher integration between the two measures. For example, French municipalities with over 20,000 inhabitants are required by law to develop local action plans (Reckien et al. 2018). However, as discussed in Section 3, one criterion for selecting the chosen cities was that they are innovative 'frontrunners' in regard to local climate change action planning. Therefore, it is believed that this hypothesis would be more advantageous to test with a larger sample of cities with differing urban properties.

The scoring system presented here could be used as a comparative metric on the level of Ad/Mit integration between CCAPs. Moreover, it could be applied as a benchmark to compare a city's CCAP with an 'ideal' CCAP that maximises the level of integration of adaptation and mitigation policies. The cities can assess the level of integration of their CCAP and include interrelationships to move towards a more integrated climate change action planning process. However, it should be clarified here that integrating adaptation and mitigation might be challenging in different policy contexts and scales in different cities (Landauer et al. 2018). Therefore, the proposed assessment framework and scoring system are not prescriptive but more supportive of cities that want to measure their level of integration of $\mathrm{Ad} / \mathrm{Mit}$ and move towards an integrated planning approach. There is some evidence that interactions of Ad/Mit actions in cities occur and cut across specific sectors, but more studies are needed to shed light on that issue.

By using the proposed evaluation framework, comprehensive reviews still need to be undertaken with an even larger number of CCAPs and similar analysis and evaluation could be conducted in other regions to get more insights on how and to which extend cities integrate adaptation and mitigation in their CCAPs. Also, there is a need for further research on the drivers and barriers of integrating adaptation and mitigation, and further understanding the correlation between the level of integration with other variables such as city's GDP, level of GHG emissions, membership in city networks, number of years active in climate change action planning, level of capacity and others. Both quantitative, based on extensive surveys, and qualitative analyses based on in-depth interviews, could address the aforementioned research issues. In addition, the quantification of interactions (synergies and trade-offs) of adaptation and mitigation measures and policies is a research field that could potentially provide essential support to urban decision-makers, urban managers and practitioners. In particular, cost-related methods such as cost-benefit and cost-effectiveness analyses could be extended to include and analyse interactions of adaptation and mitigation actions. Multicriteria evaluation and nexus studies could be also employed to quantify Ad/Mit interactions (Grafakos et al. 2016; Valek et al. 2017). 


\section{Concluding remarks}

Traditionally, adaptation and mitigation, both at the national and local level of governance, have been addressed separately, but recently, a shift towards more integrative approaches has been observed.

There has been a lack of a systematic assessment framework to evaluate the level of integration of Ad/Mit in cities' CCAPs. Our attempt was to bridge this gap by developing an assessment framework and an associated scoring system to evaluate CCAPs of nine cities that are frontrunners in climate change action planning. This is not a prescriptive framework, but it can support cities that need to employ an integrated approach in climate change action planning. The proposed framework operationalized an integrated climate change planning process in different stages and variables that further lead to scoring of CCAPs' level of Ad/Mit integration. Additionally, it was found that urban greening, water management, urban agriculture, energy and air quality management are the main urban sectors where Ad/Mit interactions occur. Future studies based on interviews and surveys could further investigate if interactions are more likely to occur in sectors that climate issues are institutionally organised within one area of operations. None of the CCAPs included any level of quantification of interactions of Ad/Mit indicating a capacity gap in cities, which can be eventually bridged by the development and utilisation of quantification techniques. Interestingly, a limited number of CCAPs addressed finance-related issues. This result points out to an interesting direction of future research on investigating whether cities allocate budgets for their mitigation, adaptation or integrated actions. In this context, this paper aims to trigger further discussion and research on the opportunities and challenges of integrating adaptation and mitigation in climate change action planning and implementation. This would support local governments on identifying the main aspects of better integration of adaptation and mitigation in their CCAPs. The application of this evaluation framework to a larger sample of cities in different regions and globally is a promising future research direction.

Acknowledgements The authors would like to thank Adrian Moredia Valek and Li Hsin Chang for their valuable technical support. Furthermore, the authors would like to thank two anonymous reviewers for their valuable comments and feedback.

OpenAccessThis article is distributed under the terms of the Creative Commons Attribution 4.0 International License (http://creativecommons.org/licenses/by/4.0/), which permits unrestricted use, distribution, and reproduction in any medium, provided you give appropriate credit to the original author(s) and the source, provide a link to the Creative Commons license, and indicate if changes were made.

\section{References}

Aguiar FC, Bentz J, Silva JMN, Fonseca A, Swart R, Santos F, Penha-Lopes G (2018) Adaptation to climate change at local level in Europe: an overview. Environ Sci Policy 86:38-63

Aguilera E, Lassaletta L, Gattinger A, Gimeno BS (2013) Managing soil carbon for climate change mitigation and adaptation in Mediterranean cropping systems: a meta-analysis. Agric Ecosyst Environ 168:25-36. https://doi.org/10.1016/j.agee.2013.02.003

Araos M, Berrang-Ford L, Ford JD, Austin SE, Biesbroek R, Lesnikowski A (2016) Climate change adaptation planning in large cities: A systematic global assessment. Environ Sci Policy 66:375-382

Aylett A (2015) Institutionalizing the urban governance of climate change adaptation: results of an international survey. Urban Clim 14(1):4-16, ISSN 2212-0955. https://doi.org/10.1016/j.uclim.2015.06.005

Baker I, Peterson A, Brown G, McAlpine C (2012) Local government response to the impacts of climate change: an evaluation of local climate adaptation plans. Landsc Urban Plan 107:127-136

Barnett J, O’Neill S (2010) Maladaptation. Glob Environ Chang 20:211-213 
Bassett E, Shandas V (2010) Innovation and climate action planning: perspectives from municipal plans. J Am Plan Assoc 76:435-450

Berry PM, Brown S, Chen M, Kontogianni A, Rowlands O, Simpson G, Skourtos M (2014) Cross-sectoral interactions of adaptation and mitigation measures. Clim Chang 128:381-393. https://doi.org/10.1007 /s10584-014-1214-0

Bizikova L, Burch S, Robinson J, Shaw A, Sheppard S (2011) Utilizing participatory scenario-based approaches to design proactive responses to climate change in the face of uncertainties. In: Climate change and policy. Springer, Berlin - Heidelberg, pp 171-190

Bosello F, Carraro C, De CE (2010) Climate Policy and the Optimal Balance between Mitigation, Adaptation and Unavoided Damage. Climate Change Economics (CCE) 1:71-92. https://doi.org/10.2139/ssrn.1594636

Broto VC, Bulkeley H (2013) A survey of urban climate change experiments in 100 cities. Glob Environ Chang 23(1):92-102

Brown C, Shaker R, Das R (2016) A review of approaches for monitoring and evaluation of urban climate resilience initiatives. Environ Dev Sustain. https://doi.org/10.1007/s10668-016-9891-7

Bryan BA, King D, Wang E (2010) Potential of woody biomass production for motivating widespread natural resource management under climate change. Land Use Policy 27:713-725. https://doi.org/10.1016/j. landusepol.2009.09.012

Buchner B, Falconer A, Hervé-Mignucci M, Trabacchi C (2012) The landscape of climate finance 2012. Climate Policy Initiatives. https:/climatepolicyinitiative.org/publication/global-landscape-of-climate-finance-2012/

Bulkeley H, Betsill M (2003) Cities and climate change: urban sustainability and global environmental governance. Routledge, London

Burch S (2010a) Transforming barriers into enablers of action on climate change: insights from three municipal case studies in British Columbia, Canada. Glob Environ Chang 20(2):287-297

Burch S (2010b) In pursuit of resilient, low carbon communities: an examination of barriers to action in three Canadian cities. Energy Policy 38(12):7575-7585

Cartwright A, Blignaut J, De Wit M, Goldberg K, Mander M, O’Donoghue S, Roberts D (2013) Economics of climate change adaptation at the local scale under conditions of uncertainty and resource constraints: the case of Durban, South Africa. Enviro Urban 25(1):1-18. https://doi.org/10.1177/0956247813477814

Charoenkit S, Kumar S (2014) Environmental sustainability assessment tools for low carbon and climate resilient low-income housing settlements. Renew Sust Energ Rev 38:509-525

Chelleri L, Minucci G, Ruiz A, Karmaoui A (2014) Responses to drought and desertification in the Moroccan Drâa Valley Region: resilience at the expense of sustainability? Int J Clim Chang Impacts Responses 5(2):17-33

Chelleri L, Waters JJ, Olazabal M, Minucci G (2015) Resilience trade-offs: addressing multiple scales and temporal aspects of urban resilience. Environ Urban 27(1):181-198. https://doi.org/10.1177 $/ 0956247814550780$

Croci E, Lucchitta B, Janssens-Maenhout G, Martelli S, Molteni T (2017) Urban CO2 mitigation strategies under the Covenant of Mayors: An assessment of 124 European cities. J Clean Prod 169:161-177

Dang HH, Michaelova A, Tuan DD (2003) Synergy of adaptation and mitigation strategies in the context of sustainable development: the case of Vietnam. Clim Pol 3(1):81-96. https://doi.org/10.1016/j. clipol.2003.10.006

de la Torre A, Fajnzylber P, Nash JD (2009) Low carbon, high growth: Latin American responses to climate change-an overview(English). World Bank Latin American and Caribbean studies. Washington, DC: World Bank. http://documents.worldbank.org/curated/en/713951468045039226/Low-carbon-high-growth-LatinAmerican-responses-to-climate-change-an-overview

Demuzere M, Orru K, Heidrich O, Olazabal E, Geneletti D, Orru H, Bhave AG, Mittal N, Feliu E, Faehnle M (2014) Mitigating and adapting to climate change: Multi-functional and multi-scale assessment of green urban infrastructure. J Environ Manage 146:107-115

Di Gregorio M, Fatorelli L, Pramova E, May P, Locatelli B, Brockhaus M (2016) Integrating mitigation and adaptation in climate and land use policies in Brazil: a policy document analysis, Centre for Climate Change Economics and Policy, Working Paper No. 257, 1-54

Duguma LA, Minang PA, Van Noordwijk M (2014a) Climate change mitigation and adaptation in the land use sector: from complementarity to synergy. Environ Manag 54:420-432. https://oi.org/10.1007/s00267-014-0331-X

Duguma LA, Wambugu SW, Minang PA, van Noordwijk M (2014b) A systematic analysis of enabling conditions for synergy between climate change mitigation and adaptation measures in developing countries. Environ Sci Pol 42:138-148, ISSN 1462-9011. https://doi.org/10.1016/j.envsci.2014.06.003

Geneletti D, Zardo L (2016). Ecosystem-based adaptation in cities: An analysis of European urban climate adaptation plans. Land Use Policy 50:38-47

Gordon D, Acuto M (2015) If cities are the solution, what are the problems? The promise and perils of urban climate leadership. In: Toly N, Schroeder H, Johnson C (eds) The urban climate challenge: rethinking the role of cities in the global climate regime. Routledge, New York p 63-81 
Gouldson A, Colenbrander S, Sudmant A, McAnulla F et al (2015) Exploring the economic case for climate action in cities. Glob Environ Chang 35:93-105

Grafakos S, Gianoli A, Tsatsou A (2016) Towards the development of an integrated sustainability and resilience benefits assessment framework of urban green growth interventions. Sustainability 8(5):461. https://doi. org/10.3390/su8050461

Grafakos S, Pacteau C, Delgado M, Landauer M, Lucon O, Driscoll P (2018) Integration of climate mitigation and adaptation: opportunities and challenges. In: Rosenzweig C, Solecki W, Romero-Lankao P, Mehrotra S, Dhakal S, Ibrahim SA (eds) Climate change and cities: second assessment report of the urban climate change research network. Cambridge University Press, Cambridge

Guyadeen D (2018) Do practicing planners value plan quality? Insights from a survey of planning professionals in Ontario, Canada. J Am Plan Assoc 84:21-32

Hansen R, Frantzeskaki N, Timon M, Emily R, Nadja K, Anna K, Jaan-Henrik K, Martina A, Stephan P (2015) The uptake of the ecosystem services concept in planning discourses of European and American cities. Ecosyst. Serv 12:228-246

Haque A, Grafakos S, Huijsman M (2011) Assessment of adaptation measures against flooding in the city of Dhaka, Bangladesh. Environ Urban 24(1):17

Heemann J, Grafakos S (2018) Do climate action plans come true? Implementation of mitigation actions and target achievement in 113 European cities. Clim. Chang, under review

Heidrich O, Dawson R, Reckien D, Walsh C (2013) Assessment of the climate preparedness of 30 urban areas in the UK. Clim Chang 120:771-784

Henstra D (2015) The tools of climate adaptation policy: analysing instruments and instrument selection. Clim Pol 16(4):496-521

Kassam A, Friedrich T, Derpsch R, Lahmar R, Mrabet R, Basch G, González-Sánchez EJ, Serraj R (2012) Conservation agriculture in the dry Mediterranean climate. Field Crop Res 132:7-17. https://doi.org/10.1016 /j.fcr.2012.02.023

Kengoum F, Tiani AM (2013) Adaptation and mitigation policies in Cameroon: pathways of synergy. Center for International Forestry Research (CIFOR), Bogor, Indonesia

Klein RJT, Schipper ELF, Dessai S (2005) Integrating mitigation and adaptation into climate and development policy: three research questions. Environ Sci Policy 8:579-588. https://doi.org/10.1016/j.envsci.2005.06.010

Klein RJT, Huq S, Denton F, Downing TE, Richels RG, Robinson JB, Toth FL (2007) Inter-relationships between adaptation and mitigation. Climate change 2007: impacts, adaptation and vulnerability. In: Parry ML, Canziani OF, Palutikof JP, van der Linden PJ, Hanson CE (eds) Contribution of working group II to the fourth assessment report of the intergovernmental panel on climate change. Cambridge University Press, Cambridge, pp 745-777

Landauer M, Juhola S, Söderholm M (2015) Interrelationships between adaptation and mitigation: a systematic literature review. Clim Chang 131:505-517. https://doi.org/10.1007/s10584-015-1395-1

Landauer M, Juhola S, Klein J(2018) The role of scale in integrating climate change adaptation and mitigation in cities. J Environ Plan Manag. https://doi.org/10.1080/09640568.2018.1430022

Leonard S, Locatelli B, Murdiyarso D, Martius C, Quina M, Baral H, (2016) A match made in Paris: adaptationmitigation synergies in the land sector. https://doi.org/10.17528/cifor/006106

Locatelli B, Catterall CP, Imbach P, Kumar C, Lasco R, Marín-Spiotta E, Mercer B, Powers JS, Schwartz N, Uriarte M (2015) Tropical reforestation and climate change: beyond carbon. Restor Ecol 23:337-343. https://doi.org/10.1111/rec.12209

McEvoy D, Lindley S, Handley J (2006) Adaptation and mitigation in urban areas: synergies and conflicts. Proc ICE-Munic Eng 159:185-192

Mechler R, Schinko T (2016) Identifying the policy space for climate loss and damage. Science 354(6310):290292. https://doi.org/10.1126/science.aag2514

Mechler R, Bouwer L, Schinko Th, Surminski S, Linnerooth-Bayer J (2019) Loss and damage from climate change: concepts, methods and policy options. Springer. https://link.springer.com/book/10.1007/978-3-31972026-5. Accessed 12 March 2019

Millard-Ball A (2012) Do city climate plans reduce emissions? J Urban Econ 71(3):289-311

Moser SC, Ekstrom JA (2010) A framework to diagnose barriers to climate change adaptation. Proceedings of the National Academy of Sciences 107 (51):22026-22031

Moser SC (2012) Adaptation, mitigation, and their disharmonious discontents: an essay. Clim Chang 111(2):165-175

Palm CA, Smukler SM, Sullivan CC, Mutuo PK, Nyadzi GI, Walsh MG (2010) Identifying potential synergies and trade-offs for meeting food security and climate change objectives in sub-Saharan Africa. Proc Natl Acad Sci:19661-19666. https://doi.org/10.1073/pnas.0912248107

Pattberg P, Widerberg O (2015) Theorising global environmental governance: key findings and future questions. J Int Stud 43(2):684-705 
Reckien D, Flacke J, Olazabal M, Heidrich O (2015) The influence of drivers and barriers on urban adaptation and mitigation plans - an empirical analysis of European cities. PLoS One 10(8):e0135597. https://oi. org/10.1371/journal.pone.0135597

Reckien et al (2018) How are cities planning to respond to climate change? Assessment of local climate plans from 885 cities in the EU-28. J Clean Prod 191:207-219

Seto K, Shobhakar D, Anthony B, Hilda B, Gian CD, David D, Luxin H, Atsushi I, Arun K, Shuaib L, Harini N, Anu R (2014) Human Settlements, Infrastructure and Spatial Planning-Climate Change 2014: Mitigation of Climate Change. Contribution of Working Group III to the Fifth Assessment Report of the Intergovernmental Panel on Climate Change. Cambridge and New York: Cambridge University

Schwarze R, Meyer PB, Markandya A, Kedia S, Maleki D, Román de Lara MV, Sudo T, Surminski S (2018) Economics, finance, and the private sector. In: Rosenzweig C, Solecki W, Romero-Lankao P, Mehrotra S, Dhakal S, Ali Ibrahim S (eds) Climate change and cities: second assessment report of the urban climate change research network. Cambridge University Press, New York In Press

Scrieuciu S, Belton V, Chalabi Z, Mechler R, Puig D (2014) Advancing methodological thinking and practice for development-compatible climate policy planning. Mitig Adapt Strateg Glob Chang 19:261-288

Shaw A, Burch S, Kristensen F, Robinson J, Dale A (2014) Accelerating the sustainability transition: exploring synergies between adaptation and mitigation in British Columbian communities. Glob Environ Chang 25:41-51

Sippel M (2011) Urban GHG inventories, target setting and mitigation achievements: how German cities fail to outperform their country. Greenhouse Gas Meas Manag 1(1):55-63

Stoorvogel JJ, Antle JM, Crissman CC, Bowen W (2004) The tradeoff analysis model: integrated bio-physical and economic modelling of agricultural production systems. Agric Syst 80:43-66. https://doi.org/10.1016/j. agsy.2003.06.002

Swart R, Raes F (2007) Making integration of adaptation and mitigation work: mainstreaming into sustainable development policies? Clim Pol 7(4):288-303

Tompkins EL, Adger WN (2005) Defining response capacity to enhance climate change policy. Environ Sci Policy 8:562-571

Tol RSJ (2005) Adaptation and mitigation: trade-offs in substance and methods. Environ Sci Pol 8(6):572-578

Valek A, Susnik J, Grafakos S (2017) Quantification of the urban water-energy nexus in México City, México, with an assessment of water-system related carbon emissions. Sci Total Environ 590-591:258-268. https://doi.org/10.1016/j.scitotenv.2017.02.234

Walsh CL et al (2013) Experiences of integrated assessment of climate impacts, adaptation and mitigation modelling in London and Durban. Environ Urban 25(2):361-380

World Bank (2010) Cities and climate change: an urgent agenda. (English). Urban development series knowledge papers; no. 10. Washington, DC: World Bank. http://documents.worldbank.org/curated/en/194831 468325262572/Cities-and-climate-change-an-urgent-agenda

Publisher's Note Springer Nature remains neutral with regard to jurisdictional claims in published maps and institutional affiliations.

\section{Affiliations}

\section{Stelios Grafakos ${ }^{1,2} \cdot$ Kate Trigg $^{1} \cdot$ Mia Landauer $^{3,4} \cdot$ Lorenzo Chelleri $^{5} \cdot$ Shobhakar $^{2}$ Dhakal $^{6}$}

1 Institute for Housing and Urban Development Studies (IHS), Erasmus University Rotterdam (EUR), Burgemeester Oudlaan 50, Rotterdam, The Netherlands

2 Global Green Growth Institute (GGGI), 21 -15 Jeongdong-gil, Jung-gu, Seoul, South Korea

3 Arctic Centre, University of Lapland, Pohjoisranta 4, 96101 Rovaniemi, Finland

4 International Institute for Applied Systems Analysis (IIASA), Schlossplatz 1, A-2361 Laxenburg, Austria

5 School of Architecture, Universitat Internacional de Catalunya (UIC), Carrer de la Immaculada 22, 08017 Barcelona, Spain

6 Department of Energy, Environment \& Climate Change, Asian Institute of Technology (AIT), Klong Luang, Pathumthani 12120, Thailand 